\title{
Association between occupation and contact allergy to the fragrance mix: a multifactorial analysis of national surveillance data
}

\author{
W Uter, A Schnuch, J Geier, A Pfahlberg, O Gefeller (for the IVDK study group
} (see acknowledgements))

\begin{abstract}
Objectives-To assess the role of potential (occupational) risk factors for fragrance contact allergy (FCA). Most studies assessing the range of contact sensitisation in various clinical populations found the fragrance mix, a good screening tool for the detection of FCA in general, to be one of the leading allergens. The role of occupational exposure to fragrances is, however, yet unclear.

Methods-Firstly, crude analyses of the prevalence of FCA in various occupational fields including all 57779 patients patch tested in the participating centres of the Information Network of Departments of Dermatology (IVDK) between January 1992 and December 1998. Secondly, a multifactorial Poisson regression analysis of these patients, including several potential risk factors.

Results-(a) The proportion of patients with FCA varied greatly between different occupational groups from $2.5 \%$ to $17.4 \%$, (b) the highest occupational risk of FCA was associated with work as a masseur or physiotherapist, metal furnace operator, potter or glass maker etc, or geriatric nurse, (c) non-occupational factors that influenced risk of FCA included atopy, female sex, several sites, in particular the axillae, and increasing age.

Conclusions-Occupations with a high risk of FCA were identified as targets of preventive action-that is, the substitution of scented products with fragrance free materials with which to work (skin disinfectants, cleaning solutions, personal care products) wherever possible.

(Occup Environ Med 2001;58:392-398)
\end{abstract}

Keywords: contact allergy; occupational risk factors; fragrances

Medical Informatics,

Biometry and

Epidemiology,

Friedrich-Alexander-

University

Erlangen-Nürnberg,

Erlangen, Germany

A Pfahlberg

O Gefeller

Correspondence to:

DrW Uter

wuter@rz.uni-osnabrueck.de

Accepted 1 March 2001 trup allergy study. ${ }^{3}$ Thus, FCA is an important public health issue.
Previous studies evaluating factors associated with a given contact sensitisation by multifactorial analysis have hinted at the usefulness of this approach to obtain estimates of the degree of association between certain risk factors while controlling for other, confounding factors. ${ }^{45}$ However, the association between certain occupations (as markers of respective occupational exposure) and a particular contact sensitisation - namely, FCA - has not yet been considered. In view of various sources of contact to scented materials in different work environments, such an analysis could contribute to occupational risk assessment, disentangling occupational and non-occupational factors. The present epidemiological study reports on the risk of FCA associated with different occupations, controlling for a different distribution of various potential confounding factors in these occupations, and attempts to provide insight into the needs for future in depth research for improving prevention of contact sensitisation to fragrances.

\section{Methods}

The Information Network of Departments of Dermatology (IVDK) surveys the epidemiology of contact allergy and has been described in detail, ${ }^{6-8}$ including its approach to the epidemiology of occupational contact dermatitis. ${ }^{9}$ Basically, all patch test results and a standardised history of all patients patch tested in the participating centres are recorded and transferred to the data centre in Göttingen at regular intervals for pooled analysis. Thus, the IVDK assesses clinical epidemiology: analyses based on data of patients referred for the evaluation of suspected contact allergy, as opposed to population based epidemiological approaches. Data management and analysis are performed with the program package SAS (Version 8.1, SAS Institute, Cary, NC).

In the present analysis, contact allergy to the fragrance mix is considered. The fragrance mix contains eight perfume compounds (oak moss, isoeugenol, eugenol, cinnamic aldehyde, geraniol, hydroxycitronellal, cinnamic alcohol, $\alpha$-amylcinnamic aldehyde, $1 \%$ each) in petrolatum as the test vehicle and is supplied by Hermal/Trolab, Reinbek, Germany. It is regarded as a relatively good screening test for FCA in general. All patients patch tested in the participating centres of the IVDK between January 1992 and December 1998 were included in this analysis.

During the several years of documentation since the beginning of the IVDK project in 
Table 1 Crude prevalences of FCA above average, defined as "at least a weak positive reaction (+)" and "at least a positive reaction (++)" at 72 hours in different occupations

\begin{tabular}{|c|c|c|c|c|c|}
\hline ISCO-88 & fob title/group & $n$ & $\% o^{\star}$ & $\begin{array}{l}+ \text { to }+++ \\
(\%)\end{array}$ & $\begin{array}{l}++ \text { to } \\
+++(\%)\end{array}$ \\
\hline 2230,3231 & Geriatric nurse & 322 & 1.209 & 17.4 & 6.2 \\
\hline 3226 & Masseur, physiotherapist & 287 & 2.921 & 16.4 & 5.9 \\
\hline 8120 & Metal furnace operator, melter, caster, drawer & 119 & 1.097 & 16.0 & 5.9 \\
\hline 7320 & Potter, glass maker, or blower & 70 & 0.879 & 15.7 & 8.6 \\
\hline 5141 & Cosmetologist & 139 & 12.981 & 14.4 & 2.9 \\
\hline $5121 \dagger$ & Household worker (including housewife) & 6820 & NC & 13.9 & 4.7 \\
\hline $6110,6120,(6200,9211)$ & Agricultural labourer & 333 & 3.187 & 13.8 & 4.2 \\
\hline $5220,5230,9110$ & Salesperson & 1013 & 0.616 & 13.3 & 4.5 \\
\hline 2300 & Teaching professional & 1498 & 1.583 & 13.1 & 3.9 \\
\hline 7311 & Precision mechanic & 153 & 1.593 & 13.1 & 3.9 \\
\hline $7430,(5200)$ & Textile worker or salesperson & 408 & 1.936 & 13.0 & 5.1 \\
\hline $3131,7344,8224$ & Photographer, laboratory worker & 108 & 3.375 & 13.0 & 1.9 \\
\hline 1000,4000 , and others & Office worker & 7779 & 1.043 & 12.2 & 4.2 \\
\hline 5123 & Waiter, bartender, etc & 471 & 1.404 & 12.1 & 3.6 \\
\hline 4211,4212 & Cashier & 125 & 1.119 & 12.0 & 4.8 \\
\hline$(5220,5230), 6113$ & Florist, gardener & 468 & 1.578 & 12.0 & 4.9 \\
\hline $9151,9322,9333$ & Package and transport labourer & 488 & 0.389 & 11.9 & 3.7 \\
\hline $7311,7343,7346$ & Printer, typesetter, and related & 187 & 1.076 & 11.8 & 4.8 \\
\hline 7213 & Sheet metal worker & 78 & 0.629 & 11.5 & 3.8 \\
\hline $2142-2147$ & Engineer & 1279 & 0.716 & 11.5 & 4.1 \\
\hline \multicolumn{2}{|c|}{ Average of all people with occupation } & 37592 & 1.337 & 11.4 & 3.9 \\
\hline
\end{tabular}

*Of all workers employed in the respective occupation(s) (average) according to the "Bundesanstalt für Arbeit" (Federal Labour Office, http://www.arbeitsamt.de) official statistics.

†ISCO-88 only includes (domestic) occupations with formal employment.

$\mathrm{NC}=$ not calculable (number of "informal" household workers unknown).

ISCO-88 number in parentheses: only part of category applicable.

1989, a patient may have been recorded more than once due to several consultations, and is identified as a different "case" each time. If there were multiple consultations of one patient, the case with the strongest reaction to the fragrance mix was selected for the present analysis. The anamnestic profile included the site of current dermatitis, information on previous or current atopic dermatitis, age, sex, the year in which the patch test was performed, and the current occupation. Occupations are registered within the IVDK primarily with the code numbers of the
Federal Statistical Bureau (maximum: three digit precision).$^{10}$ For the purpose of the present analysis, single occupations were aggregated to occupational groups if considered appropriate from the point of view of a presumably homogenous occupational exposure profile to contact with scented materials. In this paper, key international code numbers ${ }^{11}$ are given to enable international comparisons, despite some general limitations of the validity of work exposures described this way. ${ }^{12}$ Numbers of major and minor groups were padded with trailing

Table 2 Crude prevalences of FCA below average, defined as "at least a weak positive reaction (+)" and "at least a positive reaction (++)" at 72 hours

\begin{tabular}{|c|c|c|c|c|c|}
\hline ISCO-88 & fob title/group & $n$ & $\% o^{*}$ & $\begin{array}{l}+t o+++ \\
(\%)\end{array}$ & $\begin{array}{l}++ \text { to } \\
+++(\%)\end{array}$ \\
\hline \multicolumn{2}{|c|}{ Average of all people with occupation } & 37592 & 1.337 & 11.4 & 3.9 \\
\hline 3230 & Nurse, midwife & 2929 & 2.227 & 11.4 & 4.0 \\
\hline 4142 & Mail and related clerk & 219 & 1.372 & 11.0 & 4.6 \\
\hline 3221,3223 & Medical assistant & 538 & 4.315 & 10.8 & 3.2 \\
\hline $7137,7240,8282,8283$ & Electrician & 503 & 0.538 & 10.3 & 3.2 \\
\hline 2221 & Physician & 525 & 3.608 & 10.3 & 3.4 \\
\hline $3111,3116,8150,8220$ & Chemical industry technician or labourer & 399 & 1.017 & 10.3 & 2.8 \\
\hline$(5220), 8300$ & Driver, filling station attendant & 517 & 0.501 & 10.3 & 2.1 \\
\hline 2224 & Pharmacist & 108 & 1.183 & 10.2 & 3.7 \\
\hline 7212 & Welder, solderer & 90 & 0.829 & 10.0 & 5.6 \\
\hline - & Missing job title & 4629 & & 9.8 & 3.9 \\
\hline $7143,(9130,9142)$ & Cleaner & 1152 & 1.352 & 9.5 & 3.0 \\
\hline 8231 & Rubber manufacturer & 42 & 0.846 & 9.5 & 7.1 \\
\hline 7411 & Butcher, fishmonger & 227 & 1.801 & 9.3 & 4.0 \\
\hline 8211 & Metal worker (cutting) & 326 & 1.298 & 9.2 & 2.8 \\
\hline $2222,3225,(7310)$ & Dentist, dental assistant, or technician & 681 & 9.351 & 9.0 & 3.1 \\
\hline 5122,7414 & Cook, food preserver & 710 & 1.404 & 8.9 & 3.4 \\
\hline $7231-7233$ & Mechanic & 1460 & 1.165 & 8.6 & 3.2 \\
\hline 8142,8143 & Paper maker & 82 & 0.659 & 8.5 & 4.9 \\
\hline 7141,7142 & Painter, varnisher & 307 & 1.024 & 8.5 & 2.9 \\
\hline 7222,7136 & Locksmith & 740 & 0.568 & 8.4 & 3.8 \\
\hline 2450,3470 & Artist, professional sports & 215 & 1.858 & 8.4 & 2.8 \\
\hline 7412 & Baker, confectioner & 399 & 3.240 & 8.0 & 2.8 \\
\hline 5141 & Hairdresser & 866 & 5.094 & 7.9 & 2.3 \\
\hline $7440,8265,8266$ & Leather goods manufacturer & 105 & 2.105 & 7.6 & 2.9 \\
\hline 7224,8223 & Metal finisher & 81 & 1.528 & 7.4 & 3.7 \\
\hline $0000,3450,5160,9152$ & Security service & 546 & 1.524 & 7.0 & 2.7 \\
\hline 6141,9212 & Logger, forest worker & 30 & 0.549 & 6.7 & 0 \\
\hline $7121-3,7131-5,9312-3$ & Construction labourer & 872 & 0.596 & 6.1 & 2.2 \\
\hline $7124,7331,7420,8141$ & Carpenter, joiner, and other woodworker & 450 & 0.879 & 5.8 & 0.9 \\
\hline 8110,9311 & Miner & 102 & 1.005 & 4.9 & 2.0 \\
\hline 8232 & Plastic material manufacturer & 108 & 0.574 & 4.6 & 0.9 \\
\hline $6120,6151-3$ & Animal keeper & 80 & 1.570 & 2.5 & 0 \\
\hline
\end{tabular}

Footnotes as table 1. 
zeros to present four digit numbers throughout. To describe the proportion of workers in the respective occupational groups examined in the IVDK centres relative to the total number of people employed in these occupations in Germany, the mean numbers of employed people (in the period considered) were retrieved from the Federal Labour Office (http://www.arbeitsamt.de) and are shown in tables 1 and 2 .

As a first step, the proportions of people who reacted with at least a weakly positive $(+)$ reaction, and at least a positive $(++)$ reaction to the fragrance mix on the 3 rd day of the patch test were identified and aggregated on the level of current occupations and occupational groups. Results are shown in table 1 for those occupations with prevalence of FCA above average, and in table 2 for those occupations with prevalence of FCA below average.

Secondly, the association between seniority (duration of occupational exposure, categorised in the quartiles of the actual distribution) and prevalence of FCA was analysed for selected occupations and occupational groups. For this purpose, the proportions of people with FCA within the quartiles of the respective seniorities were determined.

Thirdly, Poisson regression analysis was performed. The model included all 52 occupations and occupational groups, 14 sites, age, sex, year of patch test, and atopic dermatitis (past or present, derived from the patient's history). The site of current contact dermatitis was classified according to similar previous analyses ${ }^{413}$ and clinical knowledge of particular patterns of allergic contact dermatitis to fragrances. ${ }^{14}$ Age was categorised according to the quartiles of the age distribution in our sample.

Table 3 Results of a Poisson regression analysis of patients tested with the fragrance mix between Fanuary 1992 and December 1998, considering two alternative outcomes - part I: non-occupational factors

\begin{tabular}{|c|c|c|c|c|c|}
\hline \multirow[b]{2}{*}{ Attribute } & \multirow{2}{*}{$\begin{array}{l}\text { Prevalence } \\
(\%)\end{array}$} & \multicolumn{2}{|c|}{ At least $+(11.5 \%)$} & \multicolumn{2}{|c|}{ At least $++(4.0 \%)$} \\
\hline & & $P R$ & $95 \% C I$ & $P R$ & $95 \% C I$ \\
\hline \multicolumn{6}{|l|}{ Age: } \\
\hline$\leqslant 30$ & 26.7 & 1.00 & Reference & 1.00 & Reference \\
\hline$>30-44$ & 23.8 & 1.42 & 1.31 to 1.53 & 1.61 & 1.40 to 1.84 \\
\hline$>44-58$ & 25.6 & 1.67 & 1.55 to 1.80 & 1.90 & 1.66 to 2.16 \\
\hline$>58$ & 23.9 & 1.93 & 1.77 to 2.10 & 2.07 & 1.79 to 2.39 \\
\hline Sex (female) & 64.5 & 1.29 & 1.21 to 1.37 & 1.18 & 1.07 to 1.31 \\
\hline \multicolumn{6}{|l|}{ Main site: ${ }^{\star}$} \\
\hline Trunk & 2.9 & 1.00 & Reference & 1.00 & Reference \\
\hline Hands & 29.9 & 1.24 & 1.07 to 1.46 & 1.28 & 0.98 to 1.67 \\
\hline Arm & 3.8 & 1.23 & 1.01 to 1.49 & 1.19 & 0.86 to 1.65 \\
\hline Face & 15.2 & 1.20 & 1.03 to 1.42 & 1.13 & 0.86 to 1.48 \\
\hline Neck & 1.4 & 1.39 & 1.10 to 1.75 & 1.31 & 0.88 to 1.94 \\
\hline Feet & 2.8 & 1.26 & 1.02 to 1.55 & 1.19 & 0.84 to 1.68 \\
\hline Leg & 8.7 & 1.59 & 1.36 to 1.89 & 1.50 & 1.14 to 1.99 \\
\hline Axilla & 0.9 & 2.77 & 2.20 to 3.46 & 2.73 & 1.87 to 4.00 \\
\hline Other site & 8.9 & 0.66 & 0.55 to 0.80 & 0.48 & 0.35 to 0.67 \\
\hline $\begin{array}{l}\text { Atopic dermatitis, past or } \\
\text { present }\end{array}$ & 18.1 & 1.15 & 1.07 to 1.22 & 1.14 & 1.02 to 1.28 \\
\hline \multicolumn{6}{|l|}{ Year of patch test: } \\
\hline 1992 & 10.1 & 1.00 & Reference & 1.00 & Reference \\
\hline 1993 & 13.5 & 1.46 & 1.30 to 1.63 & 1.39 & 1.15 to 1.67 \\
\hline 1994 & 15.4 & 1.71 & 1.54 to 1.91 & 1.43 & 1.19 to 1.71 \\
\hline 1995 & 15.0 & 1.30 & 1.16 to 1.45 & 1.13 & 0.94 to 1.37 \\
\hline 1996 & 15.6 & 1.33 & 1.19 to 1.49 & 1.16 & 0.96 to 1.39 \\
\hline 1997 & 15.1 & 1.43 & 1.28 to 1.60 & 1.41 & 1.18 to 1.68 \\
\hline 1998 & 15.2 & 1.58 & 1.42 to 1.76 & 1.40 & 1.17 to 1.68 \\
\hline
\end{tabular}

*Additionally controlled for several more sites-none of these associated with a significantly increased or decreased risk.
The adjusted prevalence ratios (PRs) (95\% confidence intervals (95\% CIs)) were derived from the estimates of the Poisson model to measure the strength of association estimated by the profile likelihood method. The implicit assumption when using a Poisson model for the counts of people with FCA refers to the equality of mean and variance of the response variable. In the case of overdispersion or underdispersion in the response variable (relative to the assumption of the standard Poisson model) the $95 \%$ CI underestimates or overestimates the nominal $95 \%$ CI, which has to be taken into account in the interpretation.

\section{Results}

In the period mentioned, 57779 of the 64185 patients examined in the 32 participating centres were patch tested with the fragrance mix contained in the standard series. Multiple consultations were noted in $1454(2.5 \%)$ of 57779 patients, rarely $(n=71)$ more than twice. Demographic characteristics of the whole patch test population, including time trends of certain features, have been published recently. ${ }^{15}$ The MOAHLFA index ${ }^{16}$ of the present large subset of this group is male $35.5 \%$; occupational dermatitis $15.3 \%$; atopic dermatitis $18.1 \%$; hand dermatitis $29.9 \%$; leg dermatitis $8.7 \%$; face dermatitis $15.2 \%$; and age 40 and more $57.1 \%$.

Altogether 592 additional people had been tested with the standard series, but with omission of the fragrance mix - that is, about $1 \%$ of all patients tested with the standard series. To consider potential bias by selective omission of the fragrance mix associated with certain occupations, the respective proportions were analysed. These varied unsystematically between $0.6 \%$ and $1.5 \%$.

The crude prevalences of FCA in our groups of patients with contact dermatitis working in different occupations varied considerably between the extremes, ranging from $2.5 \%$ to $17.4 \%$ (table $1 v 2$ ). A group of 15596 patients altogether with undetermined exposuremainly old age pensioners and students-was not considered in this particular analysis. When interpreting the proportions found, and the rank order, the small group sizes should be taken into account. The ranking in tables 1 and 2 , which is based on the proportion of at least a weakly positive reaction, reflects the order based on stronger reactivity relatively well, again bearing in mind the even smaller number of at least a++ positive reaction in some occupational groups. There are vast differences in the proportions of workers in the respective groups who consulted IVDK centres. This indicates selection processes (see discussion).

Seniority, the number of years spent in the occupation, and its relation to FCA has been analysed. Information on the duration of work in the current occupation had been given in $62.9 \%$ of all 57779 cases. Considerable variation of the distribution of seniority is noted: some occupations are associated with a relatively short latency period until presentation 
Table 4 Results of a Poisson regression analysis of patients tested with the fragrance mix between fanuary 1992 and December 1998, considering two alternative outcomes-part II: occupational factors

\begin{tabular}{|c|c|c|c|c|c|}
\hline \multirow[b]{2}{*}{ Current job } & \multirow{2}{*}{$\begin{array}{l}\text { Prevalence } \\
(\%)\end{array}$} & \multicolumn{2}{|c|}{ At least $+(11.5 \%)$} & \multicolumn{2}{|c|}{ At least $++(4.0 \%)$} \\
\hline & & $P R$ & $95 \% C I$ & $P R$ & $95 \% C I$ \\
\hline Engineer & 2.2 & 1.00 & Reference & 1.00 & Reference \\
\hline Metal furnace operator, etc & 0.2 & 1.42 & 0.85 to 2.23 & 1.41 & 0.64 to 3.11 \\
\hline Masseur, physiotherapist & 0.5 & 1.37 & 0.98 to 1.90 & 1.45 & 0.84 to 2.51 \\
\hline Geriatric nurse & 0.6 & 1.28 & 0.93 to 1.73 & 1.31 & 0.78 to 2.20 \\
\hline Potter, glass maker, etc & 0.1 & 1.19 & 0.58 to 2.14 & 1.66 & 0.66 to 4.17 \\
\hline Precision mechanic & 0.3 & 1.14 & 0.69 to 1.78 & 0.97 & 0.42 to 2.26 \\
\hline Photographer, etc & 0.2 & 1.07 & 0.59 to 1.78 & 0.45 & 0.11 to 1.84 \\
\hline Cosmetologist & 0.2 & 1.07 & 0.65 to 1.67 & 0.63 & 0.23 to 1.75 \\
\hline Salesperson & 1.8 & 1.02 & 0.80 to 1.29 & 1.01 & 0.67 to 1.50 \\
\hline Printer, etc & 0.3 & 1.01 & 0.63 to 1.54 & 1.14 & 0.56 to 2.31 \\
\hline Electrician & 0.9 & 0.99 & 0.71 to 1.34 & 0.94 & 0.48 to 1.47 \\
\hline Teaching professional & 2.6 & 0.98 & 0.79 to 1.22 & 0.86 & 0.59 to 1.25 \\
\hline Agricultural labourer & 0.6 & 0.97 & 0.69 to 1.35 & 0.85 & 0.47 to 1.54 \\
\hline Package and transport & 0.9 & 0.97 & 0.71 to 1.31 & 0.83 & 0.48 to 1.41 \\
\hline Sheet metal worker & 0.1 & 0.97 & 0.46 to 1.79 & 0.88 & 0.28 to 2.82 \\
\hline Florist, gardener & 0.8 & 0.96 & 0.70 to 1.30 & 1.13 & 0.69 to 1.85 \\
\hline Office worker & 13.5 & 0.95 & 0.80 to 1.14 & 0.95 & 0.71 to 1.27 \\
\hline Waiter, bartender, etc. & 0.8 & 0.94 & 0.69 to 1.28 & 0.81 & 0.47 to 1.40 \\
\hline Nurse, midwife & 5.1 & 0.92 & 0.76 to 1.13 & 0.95 & 0.68 to 1.33 \\
\hline Household worker & 11.8 & 0.89 & 0.75 to 1.08 & 0.91 & 0.68 to 1.24 \\
\hline Welder, solderer & 0.2 & 0.89 & 0.42 to 1.64 & 1.33 & 0.53 to 3.34 \\
\hline Textile worker, etc & 0.7 & 0.89 & 0.64 to 1.23 & 1.12 & 0.67 to 1.87 \\
\hline Driver, filling station attendant & 0.9 & 0.88 & 0.64 to 1.19 & 0.49 & 0.26 to 0.95 \\
\hline Mail and related clerk & 0.4 & 0.86 & 0.55 to 1.30 & 1.03 & 0.52 to 2.03 \\
\hline Missing job title & 7.9 & 0.85 & 0.70 to 1.03 & 0.95 & 0.69 to 1.30 \\
\hline Chemical industry & 0.7 & 0.85 & 0.59 to 1.20 & 0.66 & 0.35 to 1.27 \\
\hline Cashier & 0.2 & 0.84 & 0.48 to 1.39 & 0.99 & 0.42 to 2.31 \\
\hline Metal worker (cutting) & 0.6 & 0.84 & 0.56 to 1.23 & 0.67 & 0.33 to 1.35 \\
\hline Medical assistant & 0.9 & 0.82 & 0.60 to 1.11 & 0.71 & 0.41 to 1.23 \\
\hline Physician & 0.9 & 0.81 & 0.59 to 1.10 & 0.76 & 0.45 to 1.30 \\
\hline Rubber manufacturer & 0.1 & 0.80 & 0.25 to 1.89 & 1.63 & 0.51 to 5.23 \\
\hline Pharmacist & 0.2 & 0.78 & 0.40 to 1.37 & 0.83 & 0.30 to 2.31 \\
\hline Mechanic & 2.5 & 0.78 & 0.61 to 0.99 & 0.78 & 0.52 to 1.15 \\
\hline Locksmith & 1.3 & 0.78 & 0.57 to 1.04 & 0.94 & 0.59 to 1.48 \\
\hline Painter, varnisher & 0.5 & 0.77 & 0.49 to 1.14 & 0.72 & 0.36 to 1.46 \\
\hline Butcher, fishmonger & 0.4 & 0.76 & 0.46 to 1.17 & 0.94 & 0.46 to 1.91 \\
\hline Dentist, etc & 1.2 & 0.76 & 0.56 to 1.02 & 0.76 & 0.45 to 1.26 \\
\hline Baker, confectioner & 0.7 & 0.74 & 0.50 to 1.07 & 0.74 & 0.39 to 1.42 \\
\hline Cook, food preserver & 1.2 & 0.72 & 0.53 to 0.96 & 0.79 & 0.49 to 1.28 \\
\hline Artist, professional sport & 0.4 & 0.70 & 0.42 to 1.11 & 0.67 & 0.29 to 1.56 \\
\hline Cleaner & 2.0 & 0.67 & 0.52 to 0.86 & 0.62 & 0.40 to 0.96 \\
\hline Paper maker & 0.1 & 0.67 & 0.28 to 1.32 & 1.06 & 0.38 to 2.93 \\
\hline Hairdresser & 1.5 & 0.66 & 0.49 to 0.89 & 0.59 & 0.35 to 0.99 \\
\hline Security service & 1.0 & 0.63 & 0.44 to 0.89 & 0.69 & 0.39 to 1.23 \\
\hline Logger, forest worker & 0.1 & 0.61 & 0.10 to 1.91 & - & - \\
\hline Metal finisher & 0.1 & 0.61 & 0.24 to 1.27 & 0.83 & 0.26 to 2.65 \\
\hline Leather goods manufacturer & 0.2 & 0.60 & 0.27 to 1.15 & 0.63 & 0.20 to 2.03 \\
\hline Construction labourer & 1.5 & 0.54 & 0.39 to 0.74 & 0.52 & 0.31 to 0.88 \\
\hline Carpenter, etc & 0.8 & 0.53 & 0.34 to 0.79 & 0.23 & 0.08 to 0.62 \\
\hline Plastic material manufacturer & 0.2 & 0.37 & 0.13 to 0.82 & 0.20 & 0.03 to 1.48 \\
\hline Miner & 0.2 & 0.35 & 0.11 to 0.84 & 0.49 & 0.12 to 1.99 \\
\hline Animal keeper & 0.1 & 0.19 & 0.03 to 0.61 & - & - \\
\hline
\end{tabular}

with dermatitis - namely, geriatric nurses, hairdressers, cosmetologists, bakers and confectioners, cashiers, cleaners, loggers and forest workers, and package and transport labourers with a median of 6 years or less, whereas others have a much longer latency period of, for example, 15 years and more (median)namely, miners, agricultural labourers, teaching professionals, sheet metal workers, and household workers. The distribution of FCA proportions among the respective quartiles of years in an occupation does not show a consistent pattern for both outcomes considered; mostly the proportion of FCA increases with increasing seniority.

Poisson regression analysis showed several factors which were associated with a significantly increased risk of FCA (table 3 and 4). Although the role of occupational exposure to fragrances is the focus of the present paper, the other factors are nevertheless of interest and are thus shown. With increasing age, the risk of FCA increased monotonically up to a PR of
1.93 (95\% CI 1.77 to 2.10 ) for the broader and 2.07 (1.79 to 2.39 ) for the more conservative case definition, respectively, in the oldest age quartile. Female sex was associated with a slightly, yet significantly increased risk. Many sites of dermatitis considered here are significant risk factors indicative of FCA, in particular dermatitis involving the axilla, compared with the reference site trunk. Scalp, elbow, and popliteal flexures, generalised pattern, and "missing site" were additional site categories not included in table 3 and were not associated with a significantly increased or decreased risk in this analysis.

Previous or current atopic dermatitis was a significant, albeit very weak risk factor for both outcomes. Except for the year 1992, the year of patch test had no significant influence on the prevalence of positive fragrance mix test results. Interestingly, variation in time was more marked for at least a weak positive reaction than for the more conservatively defined outcome.

Significant variation in risk of FCA between the occupational groups was found for both outcomes $(p<0.0001$ for at least a weak positive reaction and $\mathrm{p}=0.004$ for at least a positive reaction). Several occupations were associated with an increased risk of FCA (based on at least a weak positive reaction) in this analysis - namely, masseur or physiotherapist, metal furnace operator, geriatric nurse, potter or glass maker etc, precision mechanic, photographer etc, cosmetologist, salesperson, and printer etc, with PRs above 1, compared with the reference group chosen (engineers), which is largely in accordance with results of the unadjusted analysis (tables 1 and 2). It should be noted, however, that although the ranking of risk estimates is definite, the actual estimates depend on the definition of the reference group, which is arbitrary (see discussion). In this case, an occupational group with a prevalence of FCA very close to the mean has been chosen.

A check of the underlying distributional assumption of the Poisson regression model showed evidence for some underdispersion in both models, more pronounced for the more restrictive case definition (scaled deviance of 0.631 and 0.407 in the two models, respectively). This means that the computed $95 \%$ CIs are too wide and represent a conservative upper bound for the true precision of the adjusted PR. We refrained, however, from incorporating the underdispersion into the model (by a suitable scaling factor), as such a late adjustment for underdispersion gives too optimistic an impression of the precision of estimates.

\section{Discussion}

Fragrances are ubiquitous substances and there are numerous chances of contact both in work and in private environments. ${ }^{1}$ The fragrance mix is a mixture of eight single fragrance materials still used commonly ${ }^{17}$ which for decades have been identified as potential allergens. ${ }^{14}$ At the same time, the mix is considered to be a relatively good screening 
tool for the detection of FCA in general, ${ }^{18}$ not only of contact allergy to one of its constituents. In populations who have had clinical patch tests it is usually the most common contact allergen after nickel. ${ }^{1}$ On the population level, FCA will be rarer than in a population selected for morbidity of suspected allergic contact dermatitis. As a consequence, the positive predictive values of positive patch test results of the fragrance mix will be lower, which can seriously limit the validity of analyses such as ours if using a sample based on a population as opposed to a clinical sample.

The number of workers from a certain occupational group consulting one of the IVDK centres for diagnostic patch testing relative to the mean number of people employed in these occupations in Germany varied considerably between the different occupational groups (tables 1 and 2). There are probably many reasons for this.

- The risk of contact dermatitis varies considerably between occupations and thus renders people more or less likely to consult one of the IVDK centres.

- Some occupations are associated with a well known high risk of sensitisation to a relatively well defined set of allergens-for example, the hairdressing trade-which may enable adequate diagnosis already on the level of primary dermatological care. This could introduce some bias in underrepresentation in the IVDK centres by selective nonreferral for patch testing.

- Access to healthcare institutions may generally be easier for some workers (including those working in the healthcare sector) than for others.

However, the contribution of these factors to overall or specific occupation selection cannot be measured well. Thus, our analysis could not incorporate such factors effectively and the interpretation of our findings based on a sample unrepresentative of the whole population has to be cautious, paying due attention to the potentially biasing effect of selection.

This unprecedented analysis of clinical surveillance data on contact allergies puts the role of occupation - as a surrogate for more specific occupational exposures-on the development of FCA into the perspective of other risk factors for this particular type of contact allergy by controlling for them in a multivariable analysis.

A first, unadjusted analysis (tables 1 and 2) showed a threefold range of prevalence of FCA, if some smaller occupational groups were disregarded. However, it is well known that occupations may differ greatly in distribution of sex and age, comparing, for example, hairdressers (predominantly young women) and construction workers (predominantly men). Thus, the proportion of FCA in different occupations could be determined more by these factors-or the actual exposures they represent - than by occupational exposure, and estimates of association may be confounded by such factors. Standardisation for age and $\mathrm{sex}^{19}$ may circumvent this problem to a certain degree, but additional factors - such as atopy or time of patch testing-may also act as confounders, if they are both associated with the outcome and one of the explanatory factors of interest. This was the reason for performing a multivariable analysis.

The results of the Poisson regression analysis clearly show that there is roughly a threefold variation in risk of FCA between high and low risk occupations, after controlling for other important risk factors. The absolute values of point estimates (PRs) should not be taken at face value, because they depend on the definition of the reference group, which is arbitrary, especially with a nominally scaled attribute, which has no natural end point as a potential reference. However, the ranking and the degree of variation in risk can be regarded as valid. In this case, we opted for a reference group with about average prevalence of FCA for both outcomes. As a consequence, risk, measured as PRs is distributed around this reference. Still, we found significant variation of prevalance (risk) of FCA between occupations when adjusting for the other, potentially confounding factors. In conclusion, we think that it is justified to identify the four occupations with highest risk for both outcomes as targets of further in depth research and prevention (see later).

Weak positive reactions to the fragrance mix may be irritant rather than allergic in some cases. Therefore, a separate analysis, with the same set of explanatory variables, was performed with a more conservatively defined outcome-at least a positive reaction. A comparison between risk estimates for these two outcomes is reassuring in that no important differences were noted: risk estimates are mostly similar-taking into account their limited precision - with a few exceptions such as textile workers, drivers and filling station attendants, and carpenters etc (table 4).

Aimed testing of an allergen may introduce heavy bias, if the reason for aimed testing-for example, working in a certain occupation-is included in the set of explanatory variables. However, in the fragrance mix there is no such effect, as this mix is tested routinely in the standard series, which is an essential part of the patch test programme for every patient, irrespective of occupation. Likewise there is no detectable downward bias due to aimed omission of the mix from the individual patch test panels related to the occupation of the patient.

Looking at the four occupations which are associated with the highest risk of FCA, harmful occupational exposures can be pinpointed to certain, more or less specific work materials in two of these. In the case of masseurs and physiotherapists, the range of work exposures has recently been reviewed. ${ }^{20}$ The authors emphasised the role of irritation by friction and cumulative exposure to emulsifiers and certain lipids, which may enhance penetration of allergens, not to mention the importance of primary irritant dermatitis as a percursor for second stage allergic contact dermatitis to fragrances, ${ }^{1}$ which abound in massage lotions and related products.

Geriatric nurses are people who work taking personal care of elderly people in the home or 
in institutions. In either case they perform various tasks which include, among others, (a) contact with wetness and irritants such as washing solutions, $(b)$ frequent disinfection of the hands, and (c) appliance of body care products and external drugs. ${ }^{21}$ All three categories of products are usually perfumed. Thus, the exposure pattern is similar to that of masseurs and physiotherapists, except for the lack of friction, and the risk of primary irritant contact dermatitis is also high. Interestingly, nurses working in patient care (international standard classification of occupations (ISCO)-88: 3230) have a lower prevalence of FCA-possibly (partly) due to some dilution bias introduced by relative overconsultation (already discussed). Specific reasons for this difference are difficult to assess by analysing surveillance data, but should be elucidated by-for example, a cross sectional epidemiological study focusing on relevant exposures.

By contrast, the high risk found for metal furnace operators, casters, etc is surprising and cannot be easily explained on the grounds of our data. Five of the 19 positive reactions (from weak to strong) occurred in a group of only 24 patients tested in Dortmund, thus, a local or regional factor-such as the use of a heavily scented body lotion-as previously reported for a group of coal miners in Nottinghamshire, ${ }^{22}$ may possibly have contributed to the effect found. Similarly, scented compounds have not yet been identified as playing a major part in occupational dermatitis of potters, glass makers, and blowers. ${ }^{23}$

On the other hand, several occupations were found to be associated with a low risk of FCA. At least some of these share similarities which may be relevant to the risk of FCA (table 2). Firstly, construction labourers, and carpenters and joiners, two large groups, are blue collar jobs traditionally chosen by men. Although the risk of irritant contact dermatitis as a potential precursor of contact sensitisation and subsequent allergic contact dermatitis is certainly not low, there is much less contact with scented material beyond an everyday level as-for example, protective emollients, which may be scented, are usually applied by a few in these occupations only. Hairdressing, by contrast, is traditionally chosen by women with a lower class background, at least in Germany. It is characterised by very heavy, largely unprotected exposure to wet work and also to a multitude of heavily scented work products, which many hairdressers apply to themselves as well. Therefore, it is surprising that hairdressers do not have an increased risk of FCA. One speculative explanation could be the heavy exposure to competing, even more aggressive allergens well known in this occupation, which cause allergic contact dermatitis and induce presentation for patch testing before FCA develops (note that the current, and not a previous employment, was used to classify occupation).

The main risk factor of general importance is age, which reflects increasing risk with cumulative lifetime exposure to fragrances. As age is highly correlated with years in occupations (albeit with a different underlying age distribution in different occupations) it will have confounded the respective analysis. It is thus surprising that a steady increase in prevalence of FCA is not always found with increasing seniority in such an analysis. This may point to cohort effects - cohorts are defined in this case as people taking up a given occupation in the same period-with a similar exposure which has presumably increased over time, whereas people with a longer occupational history may have reached higher, more administrative positions which lessened their exposure. Of course, selection processes-as a variation of the healthy worker effect-may also play a part in biasing estimates of frequency of FCA downwards for those remaining at work until they eventually get sick and present for patch testing.

Age is, in the Poisson regression analysis, not confounded by stasis dermatitis, which occurs mostly in the older age groups, as this factor has separately been taken into account $(45.9 \%$ and $23.6 \%$ stasis dermatitis, respectively, in the oldest and second oldest age groups). For the site of dermatitis, a roughly threefold risk is found in patients with dermatitis of the axilla, most likely due to the application of deodorants and antiperspirants in this region with several predisposing factors. ${ }^{14}$ Leg (stasis) dermatitis is a well known risk factor for the acquisition of contact sensitisation to many ingredients of topical drugs and ointments applied to that region. ${ }^{5}$ Also, hand and face dermatitis were associated with an increased risk of FCA, compared with the reference region chosen, which is in line with previous clinical experience 1 - both sites can be regarded as more heavily exposed to emollients and similar products than other regions of the body.

In conclusion, for those occupations identified to be associated with an increased risk, exposure to fragrances should be reduced for primary prevention of FCA - for example, by using truly fragrance free products whenever possible ${ }^{2}$ - to lessen the burden of occupational exposure. Due to the ubiquity and complexity of fragrances, this approach calls for a concerted action of the fragrance industry and its research institution (IFRA), manufacturers of work materials and skin care products containing fragrances used occupationally, and occupational physicians monitoring the application of these alternative products at the workplace. In those occupations where relevant contact to fragrances is less obvious, studies should aim to pinpoint relevant exposures.

Centres of the IVDK contributing to this analysis (in alphabetical order): Aachen (H Dickel), Augsburg (O Hirschsteiner, A Ludwig), Berlin Benjamin-Franklin (B Tebbe, R Treudler), Berlin Charité (B Laubstein, J Grabbe, T Zuberbier), Berlin UKRV (J Grabbe, T Zuberbier), Dortmund (PJ Frosch, B Pilz, C Pirker), Dresden (G Richter), Duisburg (J Schaller), Erlangen (K-P Peters, M Fartasch), Essen (H-M Ockenfels, U Hillen), Göttingen (Th Fuchs, J Geier), Graz (W Aberer, B Kränke), Halle (G Gaber, D Lübe), Hamburg (M Kiehn D Vieluf), Halle (G Gaber, D Lübe), Hamburg (M Kiehn, D Vieluf), Heidelberg (A Schulze-Dirks, M Hartmann), Homburg/Saar (P Koch), Jena (M Gebhardt, A Bauer), Kiel (J Brasch), Lübeck (J Kreusch, J Grabbe), Magdeburg (U Jappe, E Weisshaar), Mainz (D Becker), Marburg (I Effendy), München LMU (F Enders, B Przybilla, F Rueff), München Schwabing (M Agathos),
München TU (J Rakoski), Nürnberg (I Müller), Osnabrück (W 
Uter), Rostock ( $\mathrm{H}$ Heise), Tübingen (G Lischka), Ulm ( $\mathrm{H}$ Gall†), and Wuppertal (O Mainusch, J Raguz).

1 DeGroot AC, Frosch PJ. Adverse reactions to fragrances. A clinical review. Contact Dermatitis 1997;36:57-86.

2 Scheinmann PL. The foul side of fragrance-free products: What every clinician should know about managing patients with fragrance allergy. $\mathcal{f}$ Am Acad Dermatol 1999;41:1020 with

3 Nielsen NH, Menné T. Allergic contact sensitization in an unselected Danish population: the Glostrup allergy study, Denmark. Acta Dermatol Venerol (Stockh) 1992;72:456-60.

4 Christophersen J, Menne T, Tanghoj P, et al. Clinical patch test data evaluated by multivariate analysis. Danish Contact Dermatitis Group. Contact Dermatitis 1989;21: 291-9.

5 Nethercott JR, Holness DL, Adams RM, et al. Multivariate analysis of the effect of selected factors on the elicitation of patch test response to 28 common environmental contactants in North America. Am $\mathcal{F}$ Contact Dermat 1994;5:13-8.

6 Uter W, Diepgen TL, Arnold R, et al. The informational network of departments of dermatology in Germany: a multicenter project for computer-assisted monitoring of multicenter project for computer-assisted monitoring of contact allergy: electronic data processing

7 Uter W, Schnuch A, Geier J, et al. The epidemiology of contact dermatitis. The information network of departments of dermatology (IVDK) in Germany. Eur f Dermatol 1998;8 $36-40$

8 Schnuch A, Lehmacher W. Epidemiologische Überwachung des Kontaktekzems: Darstellung des Projektes "Informationsverbund Dermatologischer Kliniken" (IVDK) in Anlehnung an die "guidelines for evaluating surveillance systems" of the center of disease control (CDC). Dermatosen in Beruf und Umwelt 1992;40:177-89.

9 Schnuch A, Uter W. The role of clinical epidemiology in the study of occupational contact dermatitis. In: Kanerva L, Elsner P, Wahlberg JE, et al, eds. Textbook of occupational dermatology. Berlin: Springer, 2000:17-26.

10 Bundesamt für Statistik. Klassifizierung der Berufe: Systematisches und alphabetisches Verzeichnis der Berufsbenennungen. Wiesbaden: Bundesamt, 1992
11 International Labour Organisation. International standard classification of occupations-ISCO-88. Geneva: ILO, 1990.

12 Uter W. Classification of occupations. In: Kanerva L, Elsner $\mathrm{P}$, Wahlberg JE, et al, eds. Textbook of occupational dermatology. Berlin: Springer, 2000:27-31.

13 Nethercott JR, Holness DL, Adams RM, et al. Patch testing with a routine screening tray in North America, 1987-9: IV occupation and response. Am f Contact Dermat 1991;2: $247-54$

14 Larsen WG. Perfume dermatitis. A study of 20 patients. Arch Dermatol 1977;113:623-6.

15 Uter W, Geier J, Schnuch A. The MOAHLFA index in 17 centers of the information network of departments of dermatology (IVDK) during 6 years. Contact Dermatitis 1999; 41:343-4

16 Schnuch A, Geier J, Uter W, et al. National rates and regional differences in sensitization to allergens of the standard series. Contact Dermatitis 1997;37:200-9.

17 Johansen JD, Rastogi SC, Andersen KE, et al. Content and reactivity to product perfumes in fragrance mix positive and negative eczema patients. A study of perfumes used in toiletries and skin-care products. Contact Dermatitis 1997; 36:291-6.

18 Larsen W, Nakayama H, Lindberg M, et al. Fragrance contact dermatitis: a worldwide multicenter investigation (part I). Am ₹ Contact Dermat 1996;7:77-83.

19 Schnuch A. PAFS: population-adjusted frequency of sensitization. (I). Influence of sex and age. Contact Dermatitis 1996;34:377-82.

20 We $\beta$ becher R, Straube M, Szliska C, et al. Anamneseauxilium und gewerbedermatologische Beurteilung bei medizinischen Bademeistern, Masseuren und Physiotherapeuten. Hautarzt 1998;49:912-9.

21 Proske S, Uter W, Schwanitz HJ. Risikoberuf Altenpflege. Ergebnisse einer klinischen Studie mit gewerbedermatologischem Anamnese-Auxilium. Dermatologie in Beruf und Umwelt / Occupational and Environmental Dermatologly 2000;48:171-8.

22 Goodfield MJ, Saihan EM. Fragrance sensitivity in coal miners. Contact Dermatitis 1988;18:81-3.

23 Kanerva L, Elsner P, Wahlberg JE, et al. Handbook of occupational dermatology. Berlin: Springer, 2000.

\section{Vancouver style}

All manuscripts submitted to Occup Environ Med should conform to the uniform requirements for manuscripts submitted to biomedical journals (known as the Vancouver style.)

Occup Environ Med, together with many other international biomedical journals, has agreed to accept articles prepared in accordance with the Vancouver style. The style (described in full in the $\mathcal{F} A M A[1]$ ) is intended to standardise requirements for authors, and is the same as in this issue.

References should be numbered consecutively in the order in which they are first mentioned in the text by Arabic numerals on the line in square brackets on each occasion the reference is cited (Manson[1] confirmed other reports[2][3][4][5]). In future references to papers submitted to Occup Environ Med should include: the names of all authors if there are three or less or, if there are more, the first three followed by et al; the title of journal articles or book chapters; the titles of journals abbreviated according to the style of Index Medicus; and the first and final page numbers of the article or chapter. Titles not in Index Medicus should be given in full.

Examples of common forms of references are:

1 International Committee of Medical Journal Editors. Uniform requirements for manuscripts submitted to biomed journals. FAMA 1993;269:2282-6.

2 Soter NA, Wasserman SI, Austen KF. Cold urticaria: release into the circulation of histmaine and eosinophil chemotactic factor of anaphylaxis during cold challenge. N Engl ₹ Med 1976;294:687-90.

3 Weinstein L, Swartz MN. Pathogenic properties of invading micro-organisms. In: Sodeman WA Jr, Sodeman WA, ing micro-organisms. In: Sodeman WA Jr, Sodeman WA, phia: W B Saunders, 1974:457-72. 